\title{
PUTTING HEALTH IN ALL POLICIES: THE NATIONAL INSTITUTE FOR WELFARE ENHANCEMENT
}

\author{
Beatriz González López-Valcárcel(*) and Vicente Ortún( ${ }^{* *}$ ) \\ $\left(^{*}\right)$ University Las Palmas de GC, Spain \\ ${ }^{* *}$ ) University Pompeu Fabra, Barcelona, Spain
}

\begin{abstract}
Welfare is a rather vague term whose meaning depends on ideology, values and judgments. Material resources are just means to enhance people's well-being, but growth of the Gross Domestic Production is still the standard measure of the success of a society. Fortunately, recent advances in measuring social performance include health, education and other social outcomes. Because "what we measure affects what we do" it is hoped that social policies will change. The movement Health in all policies and its associated Health Impact Assessment methodology will contribute to it. The task consists of designing transversal policies that consider health and other welfare goals, the short term and long-term implications and intergenerational redistributions of resources. As long as marginal productivity on health outside the healthcare system is higher than inside it, efficiency needs cross-sectoral policies. And fairness needs them even more, because in order to reduce social inequalities in health, a wide social and political response is needed.
\end{abstract}

Unless we reduce the well-documented inefficiencies in our current health care systems the welfare states will fail to consolidate and the overall economic wellbeing could be in serious trouble. In this article we sketched some policy solutions such as pricing according to net benefits of innovation and public encouragement of radical innovation besides the small type incremental and market-led innovation. We proposed an independent agency, the National Institute for Welfare Enhancement to guarantee long term fair and efficient social policies in which health plays a central role.

Keywords: Public health policies; Health Impact Assessment; Welfare; Health in All Policies

JEL codes: I18, D60, H10 
The modern Welfare State has been characterized a "a major achievement of modern civilization", although it needs some urgent reforms in order to survive [1]. In this article we suggest some. Welfare is a rather vague term whose meaning depends on ideology, values and judgments, in a similar way to fairness, equity or justice. Sen, winner of the Nobel Prize in Economics 1998, developed the capabilities approach[2, 3]. According to it, material resources -income, wealth, and commodities- are just means to enhance people's well-being. Well-being should be measured not according to what individuals actually do (functioning) but what they can do (capabilities). Poverty or poor health are capabilitydeprivations, and health is one of those substantive or basic capabilities.

Nevertheless, economic outcome (growth of the Gross Domestic Production, GDP) is still the standard measure of the success of a society. It has some serious drawbacks. For instance, it considers neither distributional issues (inequalities) nor the trade-off between economic production and environment damage (traffic jams are good for the GDP because they increase the use of gasoline). A "dream team" of economists, including Stiglitz, Nobel Prize and former director of the World Bank, and Sen, have recently published a proposal for a new metric of Economic Performance and Social Progress[4]. Their report considers eight dimensions of well-being to be measured: Material living standards (income, consumption and wealth); Health; Education; Personal activities including work; Political voice and governance; Social connections and relationships; Environment (present and future conditions); and Insecurity, of an economic as well as a physical nature. Because "what we measure affects what we do" it is hoped that advances in measuring social performance will change social policies.

The public health movement called "Health in all policies" (HIAP), which inspired (and not by chance) the public health policy of the EU during the Finish Presidency $[5,6]$ arose in the 2000s as a new paradigm. The implicit idea of intersectorality and transversality of social and health policies, however, is an old idea that can be credited to Rudolf Virchow and his 1848 report on the typhus epidemic in Upper Silesia[7]. This new paradigm requires new methodologies to measure "health impact assessment", which is not an easy task[8-10]. The practical experience with HIAP started in countries such as Sweden, the Netherlands, Canada and Australia. It is now traveling towards Southern Europe where there is already a generalized legal obligation for all public projects of infrastructure to pass an environment impact study, but not a study on health impact. It could seem paradoxical that in some countries like Spain, an impact assessment on gender issues for all public programs is compulsory by law, whilst not existing HIA.

From the perspective of the public health professionals, in order to advance in HIAP it is better to convince than to defeat. Their role is that of a hinge between the healthcare system and society[11] From the perspective of economists, the HIAP paradigm only would be justified if it improves efficiency and social welfare, and that would be the case if all improvement in welfare has a certain dose of health. Because health is a goal in public policies that should be traded-off against other goals, the HIAP could be viewed merely as a self-interest driven entity, with health professionals aiming to increase by definition their inputs. 
The valuation of health and welfare outcomes is relative. Life expectancy today is substantially longer than it was one hundred years ago. Even poor people today live much longer than wealthy people did at the beginning of the $\mathrm{XX}^{\text {th }}$ century. But poor people today live shorter lives and in poorer health than their contemporaneous rich counterparts. Unfair static inequalities in health are a frequent concern in the medical as well as in the economic literature, but there is an intergenerational dimension that is sometimes lacking in analysis and social policies[12]. Those policies have a tension between short term and long term considerations. For instance, social expenditure to protect deprived persons in years of economic crisis increases fiscal deficit and debt in the following fiscal periods. That implies an intergenerational trade-off between today and tomorrow. Inter-generational considerations are essential in evaluating public-private partnerships in hospital investments. Private funds invested today for building public hospitals will have to be returned in the long term, and future generations will be implied. Quality of democracy should require mechanisms of reinforced consensus and social control prior to make decisions involving intergenerational cohesion.

Then the task consists of designing transversal policies that consider health and other welfare goals, the short term and long-term implications and intergenerational redistributions of resources. As long as marginal productivity on health outside the healthcare system is higher than inside it, efficiency dictates the need for cross-sectoral policies. Moreover, fairness requires an even greater multisectoral welfare approach, because in order to reduce social inequalities in health, a wide social and political response is needed.

There is strong evidence to suggest than if health spending growth continues to exceed GDP growth, severe cuts on education, social services and other non-health services goods would be required $[13,14]$. In developed countries, pathdependence, vested interested and bounded rationality have led societies to a very inefficient production of health, with a substantial waste on health care services at the same time that valuable services are not provided. Besides this, in Southern European countries the welfare state is neither efficient (therefore non sustainable) nor equitable (its not achieving one of its main objectives)[15].

\section{Towards an efficient production of health in developed societies}

Economic growth and nutrition improvements explain humankind's escape from hunger and premature death[16], although incipient public health measures were also important. The delivery of clean water and removal of wastes were behind health improvements throughout most of the $\mathrm{XX}^{\text {th }}$ century and only during these last decades, starting with antibiotics, did health care acquire protagonism[17]. However, the epidemiological revolution, starting in the 1940's, with its increase in life expectancy led to a significant increase in population. Birth rates, however, did not decline sufficiently to compensate for the increase in life expectancy. Increases in life expectancy, from the 1940's, appear to have reduced income per capita due to diminishing returns to labour, because land and physical capital are supplied inelastically [18].. In general, calculations suggest that the direct utility benefits of health improvements more than outweigh the indirect utility benefits that may 
flow through the channel of better health raising income. Thus any positive effects of health improvements on economic growth are going to be marginal in cost benefit analyses with regard to health improvements.

The key point is to establish the 'health production function' for any society at a given time in order to have an idea of the relation between impact on health and cost for different inputs: education, life-styles, ability to participate in society, inequalities reduction, employment, social support, environment, civicness, and different health services. It is easy to say that we need to assess all health policies broadly defined but in reality it seems that developed societies are contemplating a single argument in the production function: Health services. Even when the need for a more reasonable health services growth is recognized, the spectre of a lower longer-term rate of advance in medical knowledge is raised. Obviously, the incentives to invest in developing new drugs, devices and procedures would diminish because returns to investments in innovation depend on the size of the anticipated market. Therefore, some authors[19] claim that if spending reductions are to prove beneficial over time, it would be necessary to provide public money to maintain the expected rate of return of private investors. Again they raise the single argument health production function. Why not foster innovation and action in non-health services determinants? Why don't regulatory authorities across the world send a signal to investors that what society is willing to pay for drugs, devices, procedures and innovations is strictly related to its incremental costeffectiveness ratio as compared with existing alternatives? A change in the patent system that at present favours incremental innovations is required, and spending needs to be targeted according to the net benefits of innovations (patented products included). Free market enterprise would not always be capable of breakthroughs because firms chase short-term payoffs. Governments should not only more actively encourage technological change but can also expect to find a broad range of research ideas in universities with a different incentive structure than those prevailing at firms. It's a truism in the political economy of health that both controlling costs and directing innovations towards more 'valuable' areas is extremely difficult because every dollar in cost savings is a dollar less in income for one or more interest groups (industry, professionals, health care organizations...even us health related academics).

\section{Towards comprehensive and coherent long-term welfare policies in Southern Europe: The National Institute for Welfare Enhancement}

Better politics are required in many countries, particularly in Southern Europe for having more appropriate policies and better public management. World Bank indicators on the quality of governance (voice and accountability, political stability, government effectiveness, regulatory quality, rule of law and control of corruption) promote bench marking that helps to follow the lead of countries with a more efficient and equitable welfare state (Scandinavian countries and the Netherlands), which have been historically compatible with a continuous increase in productivity[20]. Due to time inconsistencies and short-sightedness, however, decisions taken by politicians and often changing administrations are not always done so in the best interest of society. This has been widely acknowledged in the 
decisions to give operational independence to the Central Banks in the management of monetary policy, in order to keep a growth compatible inflation under control.

We believe that a similar approach needs to be taken with welfare provision in Southern European countries. We propose that a truly independent body, at least as independent as the Central Banks, should be in charge of implementing a social consensus about pensions, health and social services responsible for simultaneously consolidating the welfare state and enhancing productivity. As eluded to above, a crucial motivation for this is the lessening, or indeed elimination, of dynamic inconsistency, the difficulty to commit to a long term optimal policy where decision-makers yield to short-term temptations. There is little sense in improving productivity without building a human and decent, but incentive-compatible, welfare state. Although the latter is one of society's major achievements it is not possible to consolidate a welfare state without improving productivity in a world open to competition. The 'National Institute for Welfare Enhancement' (NIWE) is this new body that aims to mix some of the functions performed in England by NICE with built-in mechanisms that rely on administrative (not political) decision making. These should implement the social consensus by automatically adjusting, for example, retirement pensions to life expectancy and present wages, to take into account the aforementioned intergenerational issues. The NICE component becomes essential to avoid dualization in society between the haves and have-not: There is no problem with individual willingness to pay, especially if you are dying and have a lot of money, regardless of the effectiveness of the services bought. A non-cost saving technological development would continue to be the main driver of the increase in health expenditures. Society can only afford the technologies with an implicit value for QALY in line with the amount that a democratic society is willing to spend on education, solidarity with other countries, or the arts. Democracy is a pre-requisite for efficiency (the goods most valued at the least cost) but also for personal fulfillment and the development of human capabilities on equal grounds.

The NICE component of the 'National Institute for Welfare Enhancement' would initially focus on the elaboration, distribution and follow-up of clinical guidelines, and on ensuring that its cost-effectiveness recommendations are put into practice. Decisions on affordability and compromises on patient-access schemes would continue at the Health Department. For example, the National Institute for Welfare Enhancement (NIWE) may come up with a solution for excellent cost-effectiveness, a cure for all cancers at $€ 5.000$ a year; it would be up to the Health Department and the society- to establish how to make it affordable. NIWE would also be the place to foster multi-sectorial and life-cycle centered social policies: Would it not be better, in order to reduce socioeconomic inequalities, to guarantee effective primary education to children with a higher risk of exclusion instead of pursuing equity solely on basis of more health care services. More is not always better. Consideration should be given to the fact that in many Southern European countries, the monthly expenditure on completely free inappropriate drug expenditures for pensioners is substantially greater than their monthly pension. Besides the NIWE's key-mission of consolidating the welfare state and increasing economic productivity, NIWE's existence in Southern European countries should 
help to improve the quality of the governance in these countries, including government effectiveness, regulation quality and control of corruption.

As Vaithianathan and Lewis highlight [21], there is potential for a negative countervailing effect of reduced democratic accountability, following the shift in decision making away from elected officials. They argue, however, that there are a number of issues where the benefits of independence warrant the costs. These include cost-effectiveness decisions influenced less by particularly strong lobbying groups or electoral voting patterns; the avoidance of unnecessary system restructuring; and more effective prioritization of patient safety issues (which are likely to be driven less by the need for politicians to placate the public about expected or random events under an independent system).

A number of democratic check and balances, such as the 'independence' of only those areas prone to dynamic inconsistency, is required because the main justification for NIWE shall be the improvement of the quality of democracy in particular and institutions in general. Holding NIWE to account is another important democratic check. Additionally, an independent inspectorate would assess standards and progress against targets, reporting directly to the Parliament. Where these were not being met, they would have the power to intervene directly. Circumstances justifying such interventions and the nature of these would need to be clearly set out in NIWE's Charter.

In summary, unless we reduce the well-documented inefficiencies in our current health care systems the welfare states will fail to consolidate and the overall economic well-being could be seriously compromised. In this article we sketched some policy solutions such as pricing according to net benefits of innovation and public encouragement of radical innovation besides the small type incremental and market-led innovation. Finally we proposed an independent agency, the National Institute for Welfare Enhancement to guarantee long term fair and efficient social policies in which health undoubtedly plays a central role.

The main policy implications of this article are summarized in Box 1. 


\section{BOX 1: POLICY IMPLICATIONS}

Better politics are required in Southern Europe for having more appropriate policies and better public management

Better marks in voice and accountability, political stability, government effectiveness, regulatory quality, rule of law and control of corruption, could help the laggards to follow the lead of Scandinavian countries and the Netherlands

Unless inefficiencies in current health systems are reduced, welfare states might fail to consolidate without improving economic productivity in a world open to competition

Unless equity in personal services is not acceptably achieved, welfare states might not be desirable for the voting population

An independent body accountable to the Parliament, such as the proposed National Institute for Welfare Enhancement (NIWE), is useful when political pressure stops a government adhering to optimal policy

NIWE shall avoid the tensions between short term political temptations and long-term considerations by achieving an intergenerational trade-off in its transversal policies that consider health and other welfare goals

NIWE, at least as independent as a Central Bank, should be in charge of implementing a social consensus on pensions, education, health and social services with a clear mandate: To consolidate the welfare state in a way compatible with the productivity improvement

NIWE would mix some of the functions performed in England by NICE with the encouragement of radical innovation, besides the market-led one, pricing according to the net benefits of innovation, and, above all, the design of transversal welfare policies 
$1 \quad$ Lindbeck A. Prospects for the Welfare State. IFN Working Paper 731. 2008. 2 Sen A. Utilitarianism and Welfarism. The Journal of Philosophy 1979;LXXVI 463-89.

3 Sen A. Commodities and Capabilities. Oxford: Oxford University Press 1985. $4 \quad$ Stiglitz J, Sen A, Fitoussi J. Report by the Commission on the Measurement of Economic Performance and Social Progress 2009.

5 European Union. Health and Social Affairs Council. Health in all policies. http://ec.europa.eu/health/ph overview/other policies/health other policies en. htm. 2006.

$6 \quad$ Ståhl T, Wismar M, Ollila E, et al. Health in All Policies. Prospects and potentials: Finnish Ministry of Social Affairs and Health 2006.

7 Taylor R, Rieger A. Medicine as social science: Rudolf Virchow on the typhus epidemic in Upper Silesia. Int J Health Serv 1985;15:547-59.

8 Mindell JS, Boltong A, Forde I. A review of health impact assessment frameworks. Public Health 2008;122:1177-87.

$9 \quad$ Lock K. Health impact assessment. BMJ 2000;320:1395-8.

10 Davenport C, Mathers J, Parry J. Use of health impact assessment in incorporating health considerations in decision making. J Epidemiol Community Health 2006;60:196-201.

11 Segura A. [Health policies (population interventions) in health services. 2008 SESPAS Report]. Gac Sanit 2008;22 Suppl 1:104-10.

12 Lopez Casasnovas G. [A vision of the future of health policies.]. Gac Sanit 2009;23:458-61.

13 Chernew ME, Hirth RA, Cutler DM. Increased spending on health care: longterm implications for the nation. Health Aff (Millwood) 2009;28:1253-5.

14 Puig-Junoy J. ¿Mas recursos para la salud? Barcelona: Elsevier-Masson 2004.

15 Sapir A. Globalization and the Reform of European Social Models. Journal of Common Market Studies, Vol 44, No 2, pp 369-390, June 2006.

16 Fogel R. The Escape from Hunger and Premature Death, 1700-2100: Europe, America and the Third World. Cambridge: Cambridge University Press 2004.

17 Cutler D, Deaton A, Lleras-Muney A. The Determinants of Mortality 2006.

18 Acemoglu D, Johnson S. Disease and development: The effects of life expectancy on economic growth. Journal of Political Economy 2007; 115(6): 925985.

19 Aaron HJ, Ginsburg PB. Is health spending excessive? If so, what can we do about it? Health Aff (Millwood) 2009;28:1260-75.

20 Lindert P. Growing Public: Social Spending and Economic Growth since the Eighteenth Century. Cambridge: Cambridge University Press 2004.

21. Vaithianathan R, Lewis G. Operational independence for the NHS. BMJ 2008; 337: 380-382. 